\title{
Associação dos polimorfismos rs53576 e rs2254298 do gene receptor da ocitocina com depressão: uma revisão sistemática
}

\author{
Association of oxytocin receptor gene polymorphisms rs53576 and rs 2254298 \\ with depression: a systematic review \\ Camila Bittencourt Jacondino', Cristiane Alves Borges ${ }^{2}$, Maria Gabriela Valle Gottlieb ${ }^{3}$ \\ ${ }^{1}$ Enfermeira. Doutoranda em Gerontologia Biomédica pela Pontifícia Universidade Católica do Rio Grande do Sul (PUCRS), Porto Alegre, RS. \\ ${ }^{2}$ Acadêmica de Ciências Biológicas pela PUCRS, Porto Alegre, RS \\ ${ }^{3}$ Bióloga. Pesquisadora e professora do Programa de Pós Graduação em Gerontologia Biomédica do Instituto de Geriatria e \\ Gerontologia da PUCRS. Programa Nacional de Pós Doutorado (PNPD). Porto Alegre, RS.
}

\section{RESUMO}

Objetivos: Embora a etiologia da depressão seja reconhecidamente multifatorial, estudos têm sugerido que esteja associada a uma mutação no gene receptor da ocitocina (OXTR). O objetivo deste estudo foi verificar, por meio de uma revisão sistemática da literatura, a ocorrência de associação dos OXTR rs53576 e rs2254298 com depressão e sintomas ou temperamento depressivo.

Métodos: A pesquisa foi realizada nas bases Lilacs, PubMed, SciELO, Web of Science, Scopus e Embase, abrangendo o período de 2004 a 2014, nos idiomas inglês e português, com o descritor gene receptor da ocitocina/oxytocin receptor gene, adicionado aos descritores depressão/ depression, temperamento depressivo/depressive temperament ou distúrbios do humor/mood disorder. Foram utilizados os seguintes critérios para a inclusão dos artigos: estudos originais com conteúdo disponível na íntegra em idioma inglês ou português; somente estudos com seres humanos com diagnóstico clínico de depressão, ou rastreamento de sintomas e temperamento depressivos; estudos com as variantes rs53576 ou rs225298 do gene OXTR; e a investigação de associação entre os polimorfismos OXTR e depressão e/ou sintomas ou temperamento depressivo.

Resultados: Foram capturados inicialmente 126 artigos, entretanto apenas oito estudos preencheram os critérios de inclusão. Dos oito artigos incluídos, seis estudos encontraram associação significativa entre as variantes OXTR rs53576 e rs2254298 com depressão, temperamento e sintomas depressivos, enquanto dois estudos não encontraram associação.

Conclusões: Os resultados sugerem que os OXTR rs53576 e rs2254298 estão associados a sintomas, temperamento depressivo e depressão. Contudo, é importante levar em consideração que esses polimorfismos não atuam de forma determinística, ou seja, são influenciados ou modulados por condições ambientais, que podem envolver fatores biopsicossociais, afetivos, étnicos e de gênero.

DESCRITORES: RECEPTORES DA OCITOCINA; OXTR; POLIMORFISMO GENÉTICO; OCITOCINA; DEPRESSÃO.

\section{ABSTRACT}

Aims: Although the etiology of depression is known to be multifactorial, studies have pointed to its association with a mutation in the oxytocin receptor gene (OXTR). The aim of this study was to determine, by means of a systematic review of the literature, whether OXTRs rs53576 and rs2254298 are associated with depression and depressive symptoms or temperament.

Methods: The survey was conducted on the databases Lilacs, PubMed, SciELO, Web of Science, Scopus and Embase, covering the period 2004-2014, in English and Portuguese, with the descriptors receptor da ocitocina/oxytocin receptor gene, added to depressão/depression, temperamento depressivo/depressive temperament, or distúrbios do humor/mood disorder. The following criteria were used for the inclusion of items: original studies with content available in full in English or Portuguese language; only human studies with clinical diagnosis of depression, or screening for symptoms and depressive temperament; studies on the variants rs53576 or rs22524298 of OXTR; and search for association between OXTR polymorphisms and depression and/or depressive symptoms or temperament.

Results: Initially 126 articles were captured, but only eight studies met the inclusion criteria. Of the eight articles included, six studies found a significant association between variants OXTR rs53576 and rs225298 with depression, mood and depressive symptoms, while two studies found no association.

Conclusions: The results suggest that OXTR rs53576 and rs2254298 are associated with depressive symptoms and temperament as well as with depression. However, it should be noted that these polymorphisms do not act deterministically; rather, they are influenced or modulated by the environment, which may involve biopsychosocial, affective, ethnic, and gender factors.

KEY WORDS: RECEPTORS, OXYTOCIN; OXTR; POLYMORPHISM, GENETIC; OXYTOCIN; DEPRESSION 


\section{INTRODUÇÃO}

A depressão pode ser definida como um transtorno comum caracterizado por tristeza, perda de interesse, ausência de prazer e oscilações entre sentimentos, de culpa e autoestima, além de distúrbios do sono ou do apetite, sensação de cansaço e falta de concentração. ${ }^{1}$ A prevalência da depressão vem atingindo proporções elevadas, configurando-se como um importante agravo de saúde pública. Acomete principalmente idosos, mulheres, portadores de doenças crônicas e pessoas de maior vulnerabilidade social. Atualmente, esse transtorno é a segunda causa de incapacidade na faixa etária de 15 a 44 anos. Estima-se que no Brasil há 17 milhões de pessoas com depressão, e a Organização Mundial da Saúde alerta que até 2020 essa doença poderá passar da quarta para segunda colocada entre as principais doenças crônicas não-transmissíveis. ${ }^{2,3}$

A etiologia e a fisiopatologia da depressão ainda podem ser consideradas de difícil compreensão. Contudo, sabe-se que a diminuição de monoaminas, como a dopamina, a serotonina e a norepinefrina estão relacionados com a fisiopatologia desse transtorno, além da exposição a condições ambientais adversas, assim como algum evento de estresse emocional e traumas ocorridos na infância. ${ }^{4,5,6}$ Além disso, estudos sugerem que a composição genética pode estar intimamente associada à ocorrência de quadros psicopatológicos, devido, principalmente, à grande quantidade de genes encontrados e que estão associados ao temperamento afetivo e distúrbios do humor como depressão e ansiedade. ${ }^{7,8}$ Estudos têm mostrado que o risco relativo para familiares de primeiro grau de indivíduos portadores de depressão é de duas a três vezes maior do que para os que não possuem história familiar de depressão e, em gêmeos, a correlação pode chegar a $40 \%{ }^{7,8}$

A ocitocina, um hormônio nonapeptídeo, é produzida por neurônios magnocelulares e parvocelulares do núcleo paraventricular e supraóptico do hipotálamo, sendo secretada pela hipófise na corrente sanguínea para atuar em funções bem conhecidas, tais como contração uterina durante o parto e ejeção do leite, e como neuro-hormônio, sendo liberada através de projeções do circuito magnocelular que estão localizadas no núcleo paraventricular e supraóptico do sistema nervoso central, atuando também como neuromodulador. ${ }^{9} \mathrm{O}$ sistema límbico, considerado como o centro das emoções, é o principal local de expressão dos receptores da ocitocina, principalmente o hipocampo e amígdala, sendo este um dos motivos da associação da ocitocina com transtornos afetivos, no comportamento maternal, social, memória social e no aumento da empatia. ${ }^{10,11}$ Estudos com mamíferos revelam que a ocitocina é responsável pela construção de comportamentos relacionados com o reconhecimento de membros da mesma espécie, na preferência pela formação de pares para o acasalamento, e na expressão de certas emoções, como medo e ansiedade. ${ }^{11,12}$

Um dos principais mecanismos pelos quais a ocitocina está envolvida na fisiopatologia da depressão é a pela diminuição da hiperatividade do eixo hipotálamo-pituitária-adrenal, ocasionada pelo cortisol, em respostas a eventos estressantes, como ansiedade, depressão e estresse pós traumático. ${ }^{13,14}$ Outra hipótese também sugerida, e que implica na ação da ocitocina na fisiopatologia dos transtornos depressivos, seria de que a ocitocina tem a propriedade de induzir o aumento da atividade serotoninérgica, inibindo os antagonistas dos receptores $2 \mathrm{~A} / \mathrm{C}$ da serotonina. ${ }^{15}$

Os efeitos centrais da ocitocina são mediados por um receptor, que consiste em uma proteína formada por nove aminoácidos acoplados à proteína $\mathrm{G} .{ }^{16} \mathrm{O}$ gene que codifica o receptor da ocitocina (OXTR - oxytocin receptor gene), o qual foi identificado pela primeira vez em 1992, por Kimura et al., ${ }^{17}$ localiza-se no braço curto do cromossomo 3p25, medindo cerca de $19 \mathrm{~kb}$ e contendo três exons e 4 introns. Posteriormente, em 1994, o OXTR foi completamente mapeado em seres humanos, por Inoe et al. ${ }^{18}$

Os polimorfismos do OXTR rs53576 e rs2254298 são variações de nucleotídeo único localizadas no terceiro intron, estando associados com o surgimento de distúrbios do comportamento, tais como transtornos de ansiedade, depressão e autismo. ${ }^{19,20,21}$ Estudos genéticos sugerem que em algum momento da evolução humana, uma mutação ocorreu substituindo a guanina $(\mathrm{G})$ por adenina (A), uma vez que o alelo A está ausente em outros primatas, o que leva à conclusão de que o $\mathrm{G}$ é o alelo ancestral. Desta forma, essas variantes do OXTR rs53576 e rs2254298 são caracterizadas por dois alelos $(\mathrm{A} / \mathrm{G})$, que originam três possíveis genótipos: heterozigoto (AG) e homozigotos (AA e GG). Dados sobre etnia demonstram que os caucasianos são em sua maioria portadores de duas cópias do alelo $\mathrm{G}$, enquanto os asiáticos apresentam uma maior frequência do alelo A e em torno de $40 \%$ deles são homozigotas para o alelo G. ${ }^{22,23}$

Estudos sugerem que pessoas portadoras do alelo A do polimorfismo do OXTR são mais susceptíveis ao desenvolvimento de transtornos do humor, como depressão e ansiedade. ${ }^{24}$ Saphire et al..$^{25}$ observaram que os indivíduos portadores do alelo A apresentavam mais frequentemente sintomas depressivos quando 
comparados aos homozigotos para o alelo $\mathrm{G}$, que eram mais otimistas e com maior autoestima. Além disso, Rodrigues et al. ${ }^{26}$ constataram, em uma população composta por 192 estudantes de uma Universidade da Califórnia, que os portadores do genótipo GG apresentavam maior empatia e maior capacidade de detectar emoção através da expressão facial, além de temperamento pró-social. Os homozigotos para o alelo A parecem ser mais vulneráveis ao transtorno de ansiedade, como foi observado em um grupo de 324 jovens chineses saudáveis. Nesse estudo foi verificada a influência do OXTR sobre a característica temperamental relacionada à ansiedade em indivíduos com genótipo AA. ${ }^{27}$ Além disso, as pessoas com esse mesmo genótipo tendem a ter piores respostas frente a situações de estresse, ${ }^{28} \mathrm{o}$ que pode facilitar o surgimento de algum transtorno depressivo.

Estas evidências sugerem que o polimorfismo do OXTR pode estar associado à expressão e pluralidade do comportamento humano. Essa associação pode explicar o motivo de determinados indivíduos apresentarem um temperamento depressivo ou serem mais susceptíveis a desenvolver sintomas depressivos e depressão. Contudo, os estudos nessa temática ainda são escassos e controversos, motivando a realização desta revisão sistemática da literatura, com o objetivo de verificar a existência de associação dos polimorfismos do OXTR rs53576 e rs2254298 com depressão, sintomas e temperamento depressivo em seres humanos.

\section{METODOLOGIA}

Foi realizada uma revisão de artigos dos últimos dez anos, compreendendo o período entre 20042014, nas bases Lilacs, PubMed, SciELO, Web of Science, Scopus e Embase, utilizando os seguintes descritores com sua definição no DeCS (Descritores em Saúde) e no MeSH (Medical Subject Headings) com seus correlatos na língua inglesa: receptor do gene da ocitocina/oxytocin receptor gene adicionado aos seguintes descritores: depressão/depression, temperamento depressivo/depressive temperament ou transtorno do humor/mood disorder.

A revisão sistemática foi realizada conforme as orientações das diretrizes do Statement for Reporting Systematic Reviews and Meta-Analyses of Studies, ${ }^{29}$ sendo norteada pela seguinte questão de pesquisa: existe associação dos polimorfismos do OXTR (variantes rs53576 e rs2254298) com sintomas e temperamento depressivo, distúrbios do humor ou depressão? Para a busca na literatura foram estabelecidos os seguintes critérios de inclusão:

- Estudos originais com conteúdo disponível na íntegra;

- População composta por seres humanos com diagnóstico clínico de depressão, ou rastreamento de sintomas e temperamento depressivos, estabelecidos por instrumentos validados na literatura;

- Idiomas inglês ou português;

- Estudos com os polimorfismos do OXTR das variantes rs53576 ou rs2254298, visto que estes possuem as mesmas cadeias de bases nitrogenadas (adenina-guanina) e, portanto, os mesmos genótipos;

- Desfecho final do artigo consiste na existência ou não de associação entre os polimorfismos dos genes receptor da ocitocina e depressão e/ou sintomas e temperamento depressivo.

Os artigos que não se encaixaram nos critérios de inclusão estabelecidos para essa revisão sistemática foram excluídos.

\section{RESULTADOS DA SELEÇÃO DOS ARTIGOS}

A busca realizada nas bases de dados supracitadas encontrou um total 126 de artigos relacionados ao tema da pesquisa. Entretanto, não foram encontrados estudos na língua portuguesa, nas bases de dados Lilacs ou Scielo. Dos 126 artigos encontrados, 118 foram excluídos, sendo que 80 foram excluídos por duplicata, ou seja, estavam presentes em mais de uma base de dados. Os outros 38 artigos foram excluídos por não se encaixarem nos critérios de inclusão: artigos com outros polimorfismos $(n=05)$, com outro desfecho que não a associação com depressão-temperamento depressivo $(n=13)$, estudos com modelos experimentais $(n=04)$, artigos de revisão $(n=06)$, apenas com ocitocina plasmática $(\mathrm{n}=03)$, estudos com o polimorfismo do OXTR, mas associado com outra psicopatologia $(n=04)$, estudos apenas com depressão $(n=03)$. Dessa forma, apenas oito artigos foram incluídos na presente revisão. O fluxograma 1 mostra as etapas da seleção dos artigos (Figura 1).

Todos os artigos selecionados eram internacionais, sendo que quatro eram dos Estados Unidos, ${ }^{25,32,34,35}$ dois da Europa (Itália e Bélgica) ${ }^{30,33} \mathrm{e}$ dois de países asiáticos (Japão e China). 27,31 Também é importante destacar o ano de publicação dos estudos: a maioria deles $(n=5)^{25,28,33,34,35}$ foram publicados nos dois últimos anos. 


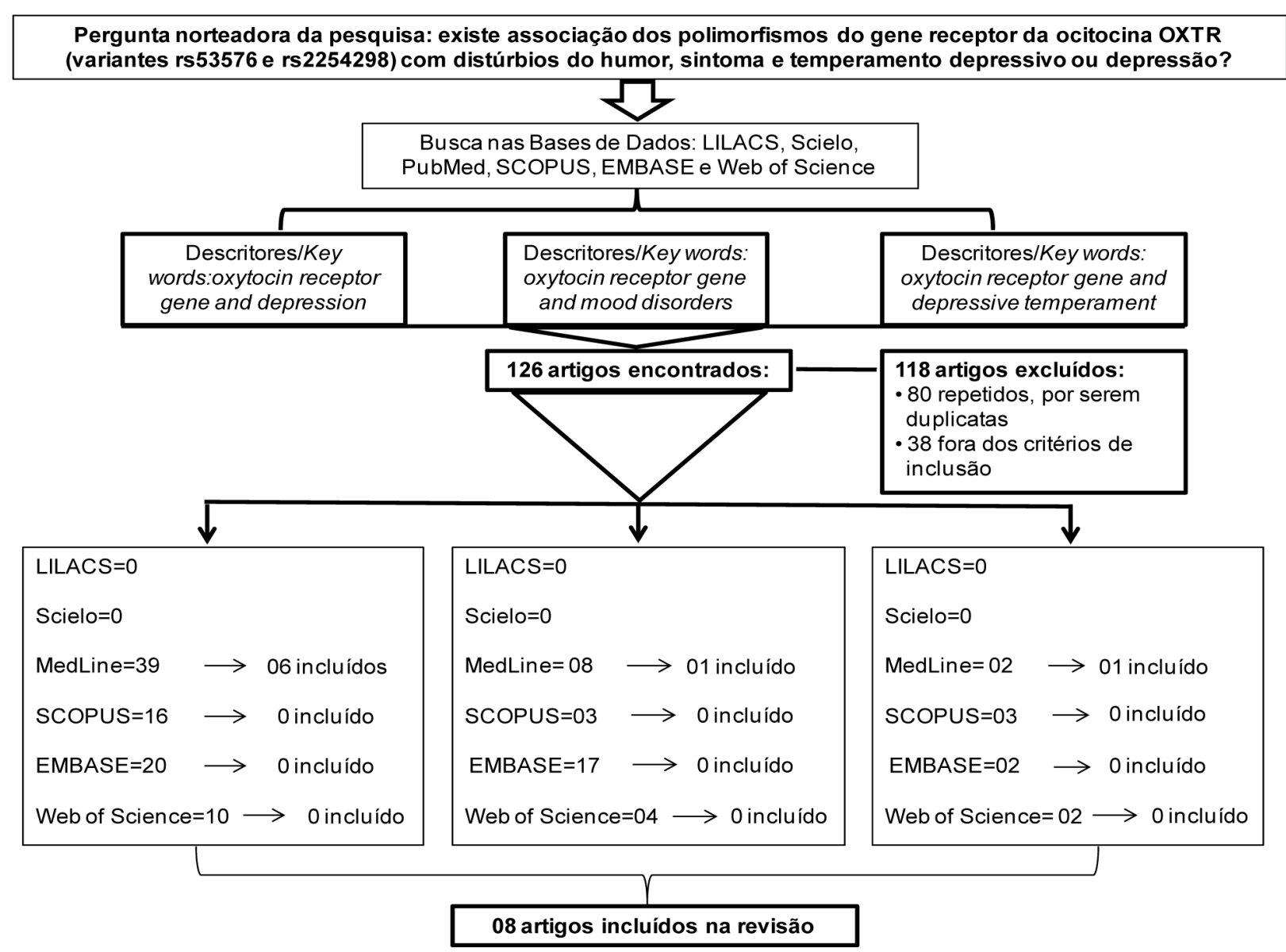

Figura 1. Sistematização da busca e seleção dos estudos sobre a associação dos polimorfismos do gene receptor da ocitocina com depressão, distúrbios do humor ou temperamento depressivo

\section{CONTEÚDO DA REVISÃO}

A maior parte dos resultados dos estudos incluídos nesta revisão sistemática demonstrou a existência de associação dos polimorfismos do OXTR rs53756 e rs2254298 com depressão, sintomas e temperamento depressivo. Em relação aos instrumentos utilizados para o rastreamento de sintomas depressivos, a Beck Depression Inventory foi aplicada em três estudos. ${ }^{25,31,35}$ Em outros dois artigos a escala de Hamilton foi utilizada para verificar o grau dos sintomas depressivos, pois os pacientes já tinham diagnóstico de depressão maior pelo DSM-IV (Manual Diagnóstico e Estatístico de Transtornos Mentais). ${ }^{30,33}$ Para mensurar o temperamento, foi utilizado em dois estudos o auto questionário para avaliação de temperamento de Memphis, Pisa, Paris e San Diego (TEMPS-A) e subescala de um instrumento tridimensional de personalidade validado para o Chinês. ${ }^{28,31}$

Dois dos oito artigos incluídos analisaram os dois polimorfismos simultaneamente (rs53576 e rs2254298), ${ }^{30,33}$ sendo que um deles, o conduzido por Mendelwicz et al. ${ }^{33}$ não encontrou associação significativa entre o OXTR rs53576 e depressão maior, mas verificou associação entre a variante rs2254298 (genótipo GG) com transtorno depressivo. Parte dos estudos incluídos encontrou associação entre a variante rs53576 com sintomas depressivos e depressão (alelo A, genótipos AA, AG e GG). ${ }^{25,30,34,35}$ E outros três estudos incluídos encontraram associação estatisticamente significativa entre o genótipo GG do OXTR rs2254298, com sintomas, temperamento depressivo e depressão maior, como pode ser observado na Tabela 1..$^{30,31,33}$

Saphire et al. ${ }^{25}$ verificaram que os portadores do alelo A apresentaram-se menos otimistas e com menor autoestima. A autoestima é considerada um preditivo de saúde física e psicológica, minimizando as respostas neurofisiológicas em resposta às situações de estresse, podendo facilitar a ligação social. Nessas situações pode haver maior liberação de ocitocina, o que pode atuar como fator de proteção a sintomas depressivos. ${ }^{36}$ 
Tabela 1. Achados dos estudos que associaram o polimorfismo do gene receptor da ocitocina rs 53576 e rs225298 com sintomas e distúrbios depressivos no período compreendido entre 2004 e 2014

\begin{tabular}{|c|c|c|}
\hline Amostra/Delineamento Instrumentos & Principais Resultados & Autor/Ano/País \\
\hline $\begin{array}{l}\text { Estudo observacional com } 185 \text { pacientes italianos } \\
\text { diagnosticados com depressão e transtorno } \\
\text { bipolar e } 192 \text { pacientes saudáveis; } \\
\text { Escala de Hamilton }\end{array}$ & $\begin{array}{l}\text { Foi encontrada associação estatística significativa } \\
\text { entre os indivíduos com depressão unipolar e o genótipo } \\
\text { GG OXTR rs53576 }(P=0,04) \text { rs2254298 }(P=0,03)\end{array}$ & $\begin{array}{l}\text { Costa et al., }{ }^{30} 2009, \\
\text { Itália }\end{array}$ \\
\hline $\begin{array}{l}\text { Estudo observacional com } 288 \text { universitários japoneses } \\
\text { de uma pesquisa de base populacional de } \\
\text { neuropsiquiatria do Japão; } \\
\text { Beck Depression Inventory (BDI); TEMPS-A }\end{array}$ & $\begin{array}{l}\text { Foi observada associação significativa entre } \\
\text { temperamentos depressivos e o genótipo } \\
\text { GG OXTR rs2254298 (P=0,045) }\end{array}$ & $\begin{array}{c}\text { Kawamura et al., }{ }^{31} 2010, \\
\text { Japão }\end{array}$ \\
\hline $\begin{array}{l}\text { Estudo observacional com } 92 \text { adolescentes americanos } \\
\text { do sexo feminino, filhas de mães com diagnóstico de } \\
\text { depressão; } \\
\text { Childrens Depression Inventory }\end{array}$ & $\begin{array}{l}\text { As meninas com genótipo AG OXTR rs } 2254298 \text {, } \\
\text { filhas de mães portadoras de depressão, apresentaram } \\
\text { sintomas de ansiedade e depressão }(P=0,01)\end{array}$ & $\begin{array}{l}\text { Tompson et al., }{ }^{32} 2010 \\
\text { Estados Unidos }\end{array}$ \\
\hline $\begin{array}{l}\text { Estudo observacional com } 186 \text { pacientes belgas com } \\
\text { diagnóstico de depressão, participantes de um estudo } \\
\text { sobre resistência ao tratamento em transtornos afetivos; } \\
\text { Escala de Hamilton }\end{array}$ & $\begin{array}{l}\text { Não foi encontrada associação significativa entre o } \\
\text { OXTR rs } 53576 \text { e depressão maior. Entretanto foi } \\
\text { encontrada associação entre transtorno depressivo } \\
\text { com a variação rs2254298, nos indivíduos do } \\
\text { genótipo GG. }(P=<0,000)\end{array}$ & $\begin{array}{c}\text { Mendelwicz et al., }{ }^{33} 2012, \\
\text { Bélgica }\end{array}$ \\
\hline $\begin{array}{l}\text { Estudo observacional com } 280 \text { universitários americanos; } \\
\text { Beck Depression Inventory (BDI) e } \\
\text { Childhood Maltreatment Questionnaire }\end{array}$ & $\begin{array}{l}\text { Indivíduos com genótipo GG rs53576, que sofreram maus } \\
\text { tratos na infância, apresentaram associação com sintomas } \\
\text { depressivos }(p=0,02)\end{array}$ & $\begin{array}{l}\text { Mc Quaid et al., }{ }^{34} 2013, \\
\text { Estados Unidos }\end{array}$ \\
\hline $\begin{array}{l}\text { Estudo observacional com } 290 \text { jovens chineses; } \\
\text { Subescala de um instrumento tridimensional de } \\
\text { personalidade validado para o Chinês }\end{array}$ & $\begin{array}{l}\text { Não houve associação significativa dos genótipos com } \\
\text { sintomas depressivos. OXTR rs53576 }\end{array}$ & $\begin{array}{l}\text { Wang et al., }{ }^{28} 2013, \\
\text { China }\end{array}$ \\
\hline $\begin{array}{l}\text { Estudo observacional com } 344 \text { estudantes americanos, } \\
\text { funcionários de uma universidade recrutados de duas } \\
\text { coortes sobre stress; } \\
\text { Beck Depression Inventory (BDI) }\end{array}$ & $\begin{array}{l}\text { Os portadores do alelo A OXTR } 53676 \text { estavam associados } \\
\text { a sintomas depressivos } p=(0,011)\end{array}$ & $\begin{array}{l}\text { Saphire et al. }{ }^{25} 2013 \\
\text { Estados Unidos }\end{array}$ \\
\hline $\begin{array}{l}\text { Estudo observacional com } 441 \text { jovens filhos de mães } \\
\text { que apresentaram depressão materna durante a infância } \\
\text { destes sujeitos; } \\
\text { Beck Depression Inventory (BDI) }\end{array}$ & $\begin{array}{l}\text { Houve associação estatisticamente significativa entre } \\
\text { depressão dos jovens portadores do genótipo AA e AG } \\
\text { do OXTR rs53576 P=0,004 }\end{array}$ & $\begin{array}{l}\text { Thompson et al., }{ }^{35} 2014 \\
\text { Estados Unidos }\end{array}$ \\
\hline
\end{tabular}

OXTR= polimorfismo do gene receptor da ocitocina

TEMPS-A = auto questionário para avaliação de Temperamento de Memphis, Pisa, Paris e San Diego.

Uma variação genética específica pode predispor ao surgimento de um estado mórbido, porém, ao associar-se a uma adversidade e a contingências ambientais, pode ter ou não efeitos deletérios, podendo inclusive causar efeitos benéficos ao comportamento. Portanto, a determinação dos fenótipos comportamentais é diretamente proporcional à interação gene-ambiente. Os indivíduos portadores de uma ou duas cópias do alelo $\mathrm{G}$ parecem ser mais susceptíveis às condições ambientais, sejam elas favoráveis ou não, ${ }^{37}$ como pode ser observado no estudo de Mac Quaid et al., ${ }^{34}$ no qual os portadores de algum alelo $G$ que sofreram maus tratos na infância de natureza psicológica ou física, apresentaram níveis elevados de sintomas depressivos. Blask et al., ${ }^{38}$ ao investigarem a associação de uma população composta por afro-americanos que sofreram maus tratos na infância, verificaram que os indivíduos homozigotos para o alelo $G$ que viviam em um ambiente social favorável apresentavam níveis mais elevados de resiliência e afeto positivo.
Dentro de uma abordagem psicológico-afetiva, desenvolver-se em um ambiente coeso e sem conflito na convivência familiar, fazendo com que o indivíduo acredite que ele é cuidado, amado e estimado, pode afetar significativamente a morbidade e a proteção para evitar transtornos psíquicos, fornecendo um suporte para o enfrentamento das situações da vida. ${ }^{39}$ Fisiologicamente, o apoio social parece ter uma relação com a ocitocina, sendo considerado um estimulante natural desse hormônio, assim como durante a relação de afeto entre mãe e filho, nas relações sociais e sexuais, são ativados os receptores da ocitocina. ${ }^{40}$

Os comportamentos sociais positivos possibilitam a redução da atividade do eixo hipotálamo e adrenal, resultando na diminuição dos estados de estresse. ${ }^{28} \mathrm{Em}$ uma pesquisa sobre a interação do polimorfismo do OXTR rs53576 com situações de estresse e efeitos do apoio social, os autores constataram que os indivíduos homozigotos ou heterozigotos para o alelo $\mathrm{G}$ apresentavam concentrações mais baixas de cortisol 
em resposta a situações de estresse psicossocial após ter recebido algum tipo de apoio social. ${ }^{26}$

Os estudos de Mendelwics et al. ${ }^{33}$ e Costa et al., ${ }^{30}$ ambos com a população caucasiana, observaram associação entre o genótipo GG, e depressão, porém, esses estudos não aplicaram outros instrumentos para verificar a presença de alguma influência do ambiente, apenas as escalas que rastreiam a depressão, sendo que ambos utilizaram o mesmo instrumento.

Nos estudos realizados por Thompson et al. ${ }^{32,35}$ observou-se que filhas de mulheres portadoras de depressão e que carregam pelo menos um alelo A, apresentaram maiores sintomas de depressão. A associação entre depressão materna e transtorno psiquiátrico das filhas sugere que a influência da saúde mental materna é maior sobre a filha do que sobre o filho. Esta situação pode ser decorrente de maior hereditariedade de depressão entre as mulheres, como foi evidenciado em uma coorte de nascidos em 1982 da cidade de Pelotas, no interior de Rio Grande do Sul. Os autores verificaram que as mulheres da amostra com transtornos mentais comuns, ou seja, sintomas depressivos e de ansiedade, eram filhas de mães com depressão. ${ }^{41}$ Tal situação pode gerar dificuldades nas relações sociais durante a infância e adolescência, favorecendo assim a predisposição para o surgimento de sintomas depressivos. ${ }^{31}$

O OXTR tem sido associado com o comportamento dos pais..$^{42}$ Os homozigotos para o alelo $\mathrm{G}$ parecem ser propensos a uma maior relação de apego e serem mais sensíveis ao choro de um bebê, como demostrou um estudo em que indivíduos OXTR-GG apresentaram reação fisiológica mais acentuada a sons repetidos de um bebê chorando, exceto os sujeitos que apresentaram sintomas de depressão. ${ }^{42}$ As mães portadoras de depressão parecem ter dificuldade em dar respostas sociais adequadas durante as interações com os seus filhos, favorecendo o surgimento de dificuldades comportamentais e emocionais ainda na primeira infância. ${ }^{43}$

A associação entre o polimorfismo do OXTR rs2254298 e temperamento depressivo foi demonstrada por Kawamura et al. ${ }^{31} \mathrm{em}$ seu estudo. Seus resultados sugerem que o OXTR pode afetar o temperamento por meio da modulação do circuito pré-frontal da amígdala. O temperamento é considerado uma tendência que o indivíduo tem para determinados padrões de reação à emoção, ou seja, a base do humor, do comportamento e da personalidade, possuindo uma base hereditária, mas podendo sofrer influências ambientais, predispondo a pessoa ao surgimento de transtornos psiquiátricos. ${ }^{44,45}$
Wang et al. ${ }^{28}$ e Mendelwiccz et al. ${ }^{33}$ não encontraram associação entre a variante OXTR rs53576 com depressão e sintomas depressivos. Porém, no estudo de Wang et al, ${ }^{28}$ as mulheres homozigóticas para o alelo A apresentaram-se com temperamento mais pessimista. Além disto, os autores verificaram, através de ressonância magnética, que essas mulheres possuíam tamanho menor da amígdala em comparação com portadores dos genótipos GG/GA..$^{28,33}$ A alteração dessa estrutura pode facilitar o surgimento de depressão, pois está relacionada com a memória emocional e social, envolvendo sentimentos de amizade, amor e relação de afeto entre as pessoas. ${ }^{46}$

Em uma metanálise, Hamilton et al. ${ }^{47}$ verificaram, através de neuroimagem, que indivíduos com depressão maior, não medicados, apresentaram anormalidade do tamanho da amígdala. É importante destacar que o polimorfismo do OXTR pode afetar o volume dessa estrutura límbica ainda na juventude, sendo uma hipótese neurobiológica da variante do OXTR como fator de risco para o desenvolvimento de psicopatologias. Nesse contexto, Furman et al. ${ }^{48}$ analisaram a associação entre o OXTR rs2254298 e o volume amigdalar, verificando que os indivíduos homozigotos para o alelo $\mathrm{G}$ apresentaram significativamente menor tamanho da amígdala em relação aos indivíduos heterozigotos e àqueles com genótipo AA. Esses resultados foram semelhantes aos observados por Tost et $\mathrm{al}^{11}$ e Inoue et $\mathrm{al}^{49}{ }^{49}$ que verificaram que os indivíduos portadores homozigotos para o alelo A apresentaram um maior tamanho da amígdala. Em ambos os estudos, com caucasianos, os sujeitos não tinham diagnóstico de qualquer transtorno de humor. Neste sentido é importante ressaltar que os estudos investigados e selecionados para a presente revisão demonstram que ambos os polimorfismos do OXTR apresentam variações nas suas frequências alélicas e genotípicas, associados a fatores étnicos.

Como pode ser observado na Tabela 2 em relação à distribuição étnica, constatou-se a predominância da população caucasiana e da cor branca em seis estudos, ${ }^{25,30,32,33,34,35}$ podendo-se verificar que tanto o alelo G quanto o genótipo GG são os mais frequentes nessas populações. Nas amostras compostas por sujeitos com descendência europeia, a maior parte tende a ser homozigota para o alelo G. Por outro lado, dados do mapeamento genético desse polimorfismo sugerem que os asiáticos sejam em sua maioria portadores do alelo A. ${ }^{23}$ Entretanto, nesta revisão, observou-se a predominância do alelo $\mathrm{G}$ nos estudos incluídos com a população asiática. ${ }^{28,31}$ Contudo, cabe salientar que no estudo de Kawamura et al..$^{31}$ as distribuições genotípicas 
Tabela 2. Frequência genotípica, étnicas raciais das amostras populacionais dos estudos que investigaram o polimorfismo do gene receptor da ocitocina rs 53576 e rs 225298 com temperamento e sintomas depressivos e depressão no período compreendido entre 2004 e 2014

\begin{tabular}{|c|c|c|c|}
\hline Título do Estudo & Autor/Ano & Frequência do genótipo & $\begin{array}{l}\text { Frequência dos } \\
\text { grupos étnicos/raciais }\end{array}$ \\
\hline $\begin{array}{l}\text { Oxytocin receptor polymorphisms and adult } \\
\text { attachment style in patients with depression }\end{array}$ & Costa et al., ${ }^{30} 2009$ & $\begin{array}{c}\text { OXTR rs53576 } \\
\text { alelo } \mathrm{G}=66 \% \\
\text { alelo } \mathrm{A}=34 \% \\
\text { OXTR rs } 2254298 \\
\text { alelo } \mathrm{G}=83 \% \\
\text { alelo } \mathrm{A}=17 \%\end{array}$ & $100 \%$ caucasianos \\
\hline $\begin{array}{l}\text { The association between oxytocin receptor gene } \\
\text { OXTR polymorphisms and affective temperaments } \\
\text { as measured by TEMPS-A }\end{array}$ & Kawamura et al., ${ }^{31} 2010$ & $\begin{array}{c}\text { OXTR rs2254298 } \\
G G=269 \\
G A=194 \\
A A=30\end{array}$ & $100 \%$ asiáticos \\
\hline $\begin{array}{l}\text { Oxytocin receptor gene polymorphism rs } 2254298 \\
\text { interacts with familial risk for psychopathology } \\
\text { to predict symptoms of depression and anxiety } \\
\text { in adolescent girl }\end{array}$ & Tompson et al., 322010 & $\begin{array}{l}\text { OXTR rs2254298 } \\
\qquad \begin{array}{l}G G=62 \\
A G=29 \\
A A=01\end{array}\end{array}$ & $\begin{array}{c}71,3 \% \text { brancos } \\
10,1 \% \text { asiáticos } \\
4,7 \%=\text { latinos } \\
3,1 \%=\text { afro-americanos }\end{array}$ \\
\hline $\begin{array}{l}\text { Influence of COX-2 and OXTR polymorphisms } \\
\text { on treatment outcome in treatment resistant } \\
\text { depression }\end{array}$ & Mendelwics et al., ${ }^{33} 2012$ & $\begin{array}{c}\text { OXTR rs53576 } \\
G G=234 \\
A A=32 \\
A G=163 \\
\text { OXTR rs } 2254298 \\
G G=166 \\
A A=09 \\
A G=163\end{array}$ & $99 \%$ caucasianos \\
\hline $\begin{array}{l}\text { Oxytocin receptor gene (OXTR) is related to } \\
\text { psychological resources }\end{array}$ & Saphire et al., ${ }^{25} 2013$ & $\begin{array}{c}\text { OXTR rs53576 } \\
\begin{array}{c}\mathrm{GG}=108 \\
\mathrm{AG}=153 \\
\mathrm{AA}=65\end{array}\end{array}$ & $\begin{array}{c}35,9 \%=\text { asiáticos } \\
26,7 \%=\text { caucasianos } \\
2,8 \%=\text { negros }\end{array}$ \\
\hline $\begin{array}{l}\text { A paradoxical association of an oxytocin receptor } \\
\text { gene polymorphism: early-life adversity and } \\
\text { vulnerability to depression }\end{array}$ & Mc Quaid et al., ${ }^{34} 2013$ & $\begin{array}{c}\text { OXTR rs53576 } \\
\mathrm{GG}=118 \\
\mathrm{AG}=119\end{array}$ & $\begin{array}{c}\text { 58\% brancos } \\
11,8 \% \text { negros } \\
8 \% \text { asiáticos } \\
5,7 \% \text { árabes } \\
\text { 7,7\% sul asiáticos }\end{array}$ \\
\hline $\begin{array}{l}\text { Neural mechanisms of oxytocin receptor gene } \\
\text { mediating anxiety related temperament }\end{array}$ & Wang et al., ${ }^{28} 2013$ & $\begin{array}{c}\text { OXTR rs53576 } \\
\mathrm{GG} / \mathrm{GA}=197 \\
\mathrm{AA}=93\end{array}$ & $100 \%$ asiáticos \\
\hline $\begin{array}{l}\text { Oxytocin receptor gene polymorphism rs } 53576 \\
\text { moderates the intergenerational transmission } \\
\text { of depression }\end{array}$ & Tompson et al., ${ }^{35} 2014$ & $\begin{array}{c}\text { OXTR rs53576 } \\
\qquad G=192 \\
A G=196 \\
A A=53\end{array}$ & $100 \%$ caucasianos \\
\hline
\end{tabular}

OXTR = polimorfismo do gene receptor da ocitocina; TEMPS-A= auto-questionário para avaliação de Temperamento de Memphis, Pisa, Paris e San Diego; COX-2= Cyclooxygenase-2.

não se encontravam em equilíbrio de Hardy-Weinberg, motivo pelo qual a diferença na frequência alélica precisa ser considerada ao se comparar estudos de populações etnicamente diferentes. Mesmo os estudos incluídos nesta revisão, com amostras de predominância caucasiana, apresentaram diferenças nas distribuições das frequências genotípicas com relação aos transtornos depressivos. Isto porque alguns estudos apresentaram associação entre o genótipo GG e sintomas depressivos, assim como em outros estudos os autores verificaram a presença da sintomatologia depressiva entre os indivíduos portadores de pelo menos uma cópia do alelo A. Tal evidência demostra que o polimorfismo OXTR pode sofrer modulação ambiental e étnica, aumentando ou não a susceptibilidade dos indivíduos ao desenvolvimento de transtornos do humor, bem como flutuações nas distribuições alélicas e genotípicas.

\section{CONSIDERAÇÕES FINAIS}

Os resultados encontrados na presente revisão sistemática sugerem que os polimorfismos do OXTR rs53576 e rs2254298 estão associados a sintomas depressivos ou temperamento depressivo e depressão. Contudo, é importante ter cautela ao estabelecer tal associação, uma vez que os resultados desses estudos ainda são insuficientes e controversos, ora encontrando associação da depressão, sintomas, e temperamento depressivo com o genótipo GG de 
ambos os polimorfismos, ora encontrando associação com o alelo A ou com os genótipos AA e AG da variante rs53576 ou com o genótipo AG da variante rs2254298. Além disso, também é fundamental levar em consideração que esses polimorfismos não atuam de forma determinística, ou seja, os mesmos são influenciados ou modulados por condições ambientais, étnicas, emocionais e afetivas. E todos esses fatores podem alterar a expressão desses polimorfismos, afetando a síntese e a liberação da ocitocina.

Uma limitação encontrada ao longo da elaboração desta revisão foi à escassez de estudos publicados com delineamento robusto (por exemplo, coorte prospectiva), impossibilitando estabelecer uma relação de causa e efeito entre os polimorfismos do OXTR e os distúrbios do humor em estudo.

São necessárias pesquisas futuras com participantes pertencentes a todas as categorias étnicas, além de verificar a influência ambiental e o contexto social a que o indivíduo está inserido, para elucidar a associação dos polimorfismos do OXTR com a depressão. Também é importante considerar os instrumentos neuropsicológicos aplicados para o rastreamento de sintomas depressivos, e o tamanho amostral de cada estudo.

\section{REFERÊNCIAS}

1. DSM-IV-TR. Manual Diagnóstico e Estatístico de Tratamento de Transtornos Mentais (2002). Porto Alegre: Artes Médicas; 2002.

2. Word Health Association. The ICD-10 Classification of Mental and Behavioral Disorders. Clinical descriptions and diagnostic guidelines. Geneva: World Health Organization; 2012.

3. Brasil. Ministério do Planejamento, Orçamento e Gestão: Instituto Brasileiro de Geografia e Estatística. IBGE. Pesquisa Nacional de Saúde 2013. [Internet] Brasília; 2013 [update 2014 dec, cited 2013 Jun 08]. Available at http://www.ibge.gov.br/home/estatistica/populacao/ pns/2013/default.shtm

4. Bottino CM, Pádua AC, Smid J, Areza-Fegyveres R, Novaretti T, Bahia VS, et al. Differential diagnosis between dementia and psychiatric disorders: Diagnostic criteria and supplementary exams. Recommendations of the Scientific Department of Cognitive Neurology and Aging of the Brazilian Academy of Neurology. Dement Neuropsychol. 2011;5(4):288-96.

5. Sadock VA, Sadock BJ. Compêndio de Psiquiatria: Ciências do comportamento e psiquiatria clínica. Porto Alegre: Artmed; 2007.

6. Agid O, Shapira B, Zislin J, Ritsner M, Hanin B, Murad H, et al. Environmental and vulnerability to major psychiatric illness: a case control study of early parent loss in major depression, bipolar disorder and schizophrenia. Mol Psychiatry.1999;4(1):163-72.

7. Hamet P, Tremblay J. Genetics and genomics of depression. Metabolism. 2005;54(Suppl 1):10-15.

8. Levinson DF. The genetics of depression: a review. Biol Psychiatry. 2006;60:84-92.

9. Francis SM, Sagar A, Levin-Decanini T, Liu W, Carter CS, Jacob S. Oxytocin and vasopressin systems in genetic syndromes and neurodevelopmental disorders. Brain Res. 2014;14:74-2.

10. Ross HE. Young LJ. Oxytocin and the neural mechanisms regulating social cognition and affiliative behavior.; Front Neuroendocrinol. 2009;30(4):534-47.

11. Tost H, Kolachana B, Verchinski BA, Bilek E, Goldman AL. Neurogenetic effects of OXTR rs 2254298 in the exthended limbic system of healthy caucasian adults. Biol Psychiatry. 2011;70(9):37-9.

12. Lee HJ, Macbeth AH, Pagani JH, Young WS. Oxytocin: The Great facilitator of life. Prog Neurobiol. 2009;88(2):127-51.

13. Sanchez Toranzo A, Frederica H. Oxitocina-vasopresina: el futuro en tratamentos. Psicofarmacolol. 2012;12(76):9-14.

14. Parker KJ, Kenna HÁ, Zeitzer JM, Keller J, Blasly CM, Amico JA et al. Preliminary evidence that plasma oxytocin levels are elevated in major depression. Psychiatry Res. 2010;178(2):359-62.

15. Barberis C, Tribollet E. Vasopressin and oxytocin receptors in the central nervous system. Crit Rev Neurobiol. 1996;10(1):119-54.

16. Gimpl G, Fahrenholz F. The oxytocin receptor system: structure, function, and regulation. Physiol Rev. 2001;81(2):629-83.

17. Kimura T, Azuma C, Saji F, Takemura M, Tokugawa Y, Miki M, et al. Oxytocin receptor gene. J Steroid Biochem Mol Biol. 1992;42:253-8.

18. Inoe T, Kimura T, Azuma C, Inazawa J, Takemura M, Kikuchi T, et al. Structural organization of the human oxytocin receptor. J Biol Chem. 1994;23(51):32451-6.

19. Zingg HH, Laporte SA. The oxytocin receptor. Trends Endocrinol Metab.2013;14(5):222-7.

20. Meyer L, Tost H. Neural mechanisms of social risk for psychiatric disorders. Nat Neurosci. 2012;15(5):663-8.

21. Ebstein RP, Israel S, Chew SH, Zhong S, Knafo A. Genetics of human social behavior. Neuron. 2010;65(6):831-44.

22. Chelala C, Khan A, Lemoine NR. SNPnexus: A web database for functional annotation of newly discovered and public domain Single Nucleotide Polymorphisms. Bioinformatics. 2009;25(5):655-66.

23. Michelini S, Urbanek M, Dean M, Goldman D. Polymorphism and genetic mapping of the human oxytocin receptor gene on chromosome 3. Am J Med Genet. 1995;60(3):183-7.

24. Brune M. Does the oxytocin receptor polymorphism (rs2254298) confer 'vulnerability' for psychopathology or 'differential susceptibility'? Insights from evolution. BMC Med. 2012;10:38. 
25. Saphire BS, Way BM, Kim HS, Sherman DK, Taylor SE. Oxytocin receptor gene (OXTR) is related to psychological resources. Proc Natl Acad Sci USA. 2011;108(37):15118-22.

26. Rodrigues SM, Saslow LR, Garcia N, John OP, Keltner D. Oxytocin receptor genetic variation relates to empathy and stress reactivity in humans. Proc Natl Acad Sci USA. 2009;106(50):21437-41.

27. Chen FS, Kumsta R, Von Dawans B, Dawans BV, Ebstein RP, Heinrichs M. Common oxytocin receptor gene OXTR polymorphism and social support interact to reduce stress in humans. Proc Natl Acad Sci USA. 2011;108(50):19937-42.

28. Wang J, Qin W, Liu B, Zhou Y, Wang D, Jiang T, et al. Neural mechanisms of oxytocin receptor gene mediating anxiety related temperament. Brain Struct Funct. 2014;219(5):1543-54

29. Liberatti A, Altman DG, Tetzlaff J, Mulrow C, Gotzsche PC, Ioannidis JP, Clarke M, Devereaux PJ, Kleijnen J, Moher D. The PRISMA statement for reporting systematic reviews and meta-analyses of studies that evaluated health care interventions: explanation and elaboration. J Clin Epidemiol. 2009;62(10):e1-34.

30. Costa B, Pini S, Gabelloni P, Abelli M, Lari L, Cardini A, et al. Oxytocin receptor polymorphisms and adult attachment style in patients with depression Psychoneuroendocrinol. 2009;34(10):1506-14.

31. Kawamura Y, Liu X, Akiyama T, Shimada T, Otowa T, Sakai Y, et al. The association between oxytocin receptor gene (OXTR) polymorphisms and affective temperaments, as measured by TEMPS-A. J Affect Disord. 2010;127:31-7.

32. Thompson RJ, Parker KJ, Hallmayer JF, Waugh CE, Gotlib IH. Oxytocin receptor gene polymorphism (rs2254298) interacts with familial risk for psychopathology to predict symptoms of depression and anxiety in adolescent girls. Psychoneuroendocrinol.2010;36(1):144-7.

33. Mendlewics J, Crisafulli C, Calati R, Kocabas NA, Massat I, Linotte S, et al. Influence of COX-2 and OXTR polymorphism on treatment outcome in treatment resistant depression. Neurosci Lett. 2012;516(1):85-8.

34. Mc Quaid RJ, Mclnnis AO, Stead JD, Matheson K. A paradoxical association of an oxytocin receptor gene polymorphism: early-life adversity and vulnerability to depression. Front Neurosci. 2013;7(128):1-7.

35. Thompson SM, Hammen C, Starr LR, Najman JM. Oxytocin receptor gene polymorphism (rs53576) moderates intergenerational transmission of depression. Psychoneuroendocrinology. 2014;43:11-9.

36. Orth U, Robins RW, Trzesniewski KH, Maes J, Schmitt M. Low self-esteem is a risk factor for depressive symptoms from young adulthood to old age. J Abnorm Psychol. 2009;118:472-8.

37. Bradley B, Davis TA, Wingo AP, Mercer KB, Ressler KJ. Family environment and adult resilience: contributions of positive parenting and the oxytocin receptor gene. European J of Psychotraumatology. 2013;4:21659.

38. Belsky J, Beaver KM. Cumulative-genetic plasticity, parenting and adolescent self-regulation. J Child Psychol Psychiat. 2011;52(5):619-26.

39. Alvarenga MRM, Oliveira MAC, Domingues MAC. Rede de suporte social do idoso atendido por equipes de saúde da família. Cienc Saúde Coletiva. 2011;16(5):2603-11.

40. Blaicher W, Gruber D, Bieglmayer C, Blaicher AM. The role of oxytocin in relation to female sexual arousal. Gynecol Obstet Invest. $1999 ; 47(2): 125-6$

41. Anselmi L, Barros F, Minten GC, Gigante DP, Horta BL, Victoria CG. Prevalência e determinantes precoce dos transtornos mentais comuns na coorte de nascimentos de 1982, Pelotas, RS. Rev Saúde Pública. 2008;42(Supl. 2):26-33.

42. Riem MM, Pieper S, Out D, Bakermans KMJ, Van Ljzendoorns MH. Social cognitive and affective. Neuroscience. 2011;6(3):294-300.

43. Mendes AV, Loureiro SR, Crippa JÁ. Depressão materna e a saúde mental de escolares. Rev Psiq Clín. 2008;35(5):178-86.

44. Ferreira, AA. Temperamentos afetivos: aspectos genéticos familiaridade e aplicação na clínica dos transtornos de humor. [thesis] [Belo Horizonte]: Universidade Federal de Minas Gerais; 2013. 99p.

45. Lara DR, Akiskal HS. Toward an integrative model of the spectrum of mood, behavioral and personality disorders based on fear and anger traits: II. Implications for neurobiology, genetics and psychopharmacological treatment. J Affect Disord. 2006;94(3):89-103.

46. Cahill L, Babinsky R, Markowitsch HJ, McGaugh JL. The Amygdala and Emotional Memory.Nature. 1995;377(6547):295-6.

47. Hamilton J, Siemer M, Gotlib I. Amygdala volume in major depression disorder: a meta-analysis of magnetic resonance imaging studies. Mol Psychiatry. 2008;13(11):993-1000.

48. Furman DJ, Chen MC, Gotlib ICH. Variant in oxytocin receptor gene is associated with amygdala volume. Psychoneuroendocrinol. $2011 ; 36(6): 891-7$.

49. Inoue H, Yamasue H, Tochigi M, Abe O, Liu X, Takei K, et al. Association between the oxytocin receptor gene and amygdalar volume in healthy adults. Biol Psychiatry. 2010;68(11):1066-72. 